\title{
Composition, size and cloud condensation nuclei activity of biomass burning aerosol from northern Australian savannah fires
}

\author{
Marc D. Mallet ${ }^{1}$, Luke T. Cravigan ${ }^{1}$, Andelija Milic ${ }^{1}$, Joel Alroe ${ }^{1}$, Zoran D. Ristovski $^{1}$, Jason Ward ${ }^{2}$, \\ Melita Keywood $^{2}$, Leah R. Williams ${ }^{3}$, Paul Selleck ${ }^{2}$, and Branka Miljevic ${ }^{1}$ \\ ${ }^{1}$ School of Chemistry, Physics and Mechanical Engineering, Queensland University of Technology, \\ Queensland, Brisbane, 4001, Australia \\ ${ }^{2}$ CSIRO Oceans and Atmosphere Flagship, Aspendale, Victoria, 3195, Australia \\ ${ }^{3}$ Aerodyne Research, Inc., Billerica, Massachusetts, 01821, USA \\ Correspondence to: Branka Miljevic (b.miljevic@qut.edu.au)
}

Received: 28 September 2016 - Discussion started: 7 October 2016

Revised: 20 February 2017 - Accepted: 21 February 2017 - Published: 14 March 2017

\begin{abstract}
The vast majority of Australia's fires occur in the tropical north of the continent during the dry season. These fires are a significant source of aerosol and cloud condensation nuclei $(\mathrm{CCN})$ in the region, providing a unique opportunity to investigate the biomass burning aerosol (BBA) in the absence of other sources. CCN concentrations at $0.5 \%$ supersaturation and aerosol size and chemical properties were measured at the Australian Tropical Atmospheric Research Station (ATARS) during June 2014. CCN concentrations reached over $10^{4} \mathrm{~cm}^{-3}$ when frequent and close fires were burning - up to 45 times higher than periods with no fires. Both the size distribution and composition of BBA appeared to significantly influence $\mathrm{CCN}$ concentrations. A distinct diurnal trend in the proportion of BBA activating to cloud droplets was observed, with an activation ratio of $40 \pm 20 \%$ during the night and $60 \pm 20 \%$ during the day. BBA was, on average, less hygroscopic during the night $(\kappa=0.04 \pm 0.03)$ than during the day $(\kappa=0.07 \pm 0.05)$, with a maximum typically observed just before midday. Size-resolved composition of BBA showed that organics comprised a constant $90 \%$ of the aerosol volume for aerodynamic diameters between 100 and $200 \mathrm{~nm}$. While this suggests that the photochemical oxidation of organics led to an increase in the hygroscopic growth and an increase in daytime activation ratios, it does not explain the decrease in hygroscopicity after midday. Modelled CCN concentrations assuming typical continental hygroscopicities produced very large overestimations of up to $200 \%$. Smaller, but still significant, overpredictions up to $\sim 100 \%$ were observed using aerosol mass
\end{abstract}

spectrometer (AMS)- and hygroscopicity tandem differential mobility analyser (H-TDMA)-derived hygroscopicities as well as campaign night and day averages. The largest estimations in every case occurred during the night, when the small variations in very weakly hygroscopic species corresponded to large variations in the activation diameters. Trade winds carry the smoke generated from these fires over the Timor Sea, where aerosol-cloud interactions are likely to be sensitive to changes in $\mathrm{CCN}$ concentrations, perturbing cloud albedo and lifetime. Dry season fires in northern Australia are therefore potentially very important in cloud processes in this region.

\section{Introduction}

Biomass burning aerosol (BBA) can act as efficient cloud condensation nuclei $(\mathrm{CCN})$ and form cloud droplets. Fires can therefore influence cloud formation, growth, reflectance, precipitation and lifetime (Kaufman et al., 1998; Warner and Twomey, 1967). The contribution of CCN from fires results in higher concentrations of cloud droplets, which yield whiter clouds that generally survive longer than clouds with fewer droplets (Platnick and Twomey, 1994). While greenhouse gases and black carbon emitted from fires absorb radiation and have a warming effect, the influence of solar radiation scattering by organic material and the production of CCN has a cooling effect on the Earth's lower atmosphere. The net forcing of carbonaceous combustion aerosol 
is thought to have an overall global cooling effect (Spracklen et al., 2011; Ward et al., 2012). The complexity arises from variability in emission factors, BBA size, composition and aging. This contributes to a large uncertainty that these fires have on the radiative budget (Carslaw et al., 2010). Thus detailed measurements of the physical and chemical properties of BBA from all regions in different seasons are essential in determining their impact on clouds (Spracklen et al., 2011). Very few studies have taken place within Australia, despite Australia contributing an estimated $15 \%$ of yearly global burned land area (van der Werf et al., 2006). Australian studies have been typically focused on fires in the southern continent (Lawson et al., 2015) or east coast cane fires (Warner and Twomey, 1967). The extent to which dry season fires in northern Australia impact CCN concentrations has not been explored in detail.

Most of central northern Australia is unpopulated and is characterized by savannah vegetation with grasslands, shrubs and scattered eucalypt trees. Although the most devastating fires burn in the densely populated southern regions of Australia, the vast majority of the continent's fires occur in the north and are responsible for more than half of land area affected by fires (Russell-Smith et al., 2007). During the dry season (May until November) thousands of fires burn via prescribed burning and natural or accidental ignitions. The frequency and severity of these fires increases as the season progresses from the early dry season to the late dry season (Andersen et al., 2005). Under Aboriginal management, fires were lit in the late dry season in order to prepare for the wet season. These late dry season fires may have been lit intentionally to trigger the onset of rainfall following the formation of pyro-cumulus clouds, among other ecological reasons (Bowman and Vigilante, 2001; Bowman et al., 2007). Under non-Indigenous management, early dry season prescribed burns are commonplace in order to reduce the severity of late dry season fires (Andersen et al., 2005). Outside of the only major urban centre in this region, Darwin, prescribed burns are the dominant source of accumulation mode aerosol particles (Mallet et al., 2016). Although long-range mineral dust sourced from the central Australian desert was observed during SAFIRED (Winton et al., 2016), the number concentrations of these particles in the sub- $200 \mathrm{~nm}$ size range was likely to be negligible. Thus these prescribed burns will dictate $\mathrm{CCN}$ concentrations in the region.

The vegetation (fuel) type, burning conditions and atmospheric aging determines the size, composition and the hygroscopicity of BBA, and in turn their ability to act as $\mathrm{CCN}$. BBA is typically a mixture of elemental carbon (EC) and organic carbon (OC) and can contain inorganic material (Reid et al., 2005). The precise OC composition of primary BBA can vary greatly depending on the fuel type and these organic constituents can be weakly or highly hygroscopic (Carrico et al., 2010; Mochida and Kawamura, 2004; Novakov and Corrigan, 1996; Petters et al., 2009). The hygroscopicity of BBA can change with oxidation and with the condensation or evaporation of volatile organic compounds (VOCs) through atmospheric aging (Hennigan et al., 2011). Smog chamber experiments have shown that after a few hours of simulated photochemical aging, the hygroscopicity of BBA converges to weakly hygroscopic for many different fuel types (Engelhart et al., 2012; Giordana et al., 2013).

While laboratory-based measurements are useful in understanding the physical and chemical processes that determine the hygroscopicity and composition of aerosol, they do not necessarily represent ambient conditions. Due to feasibility, however, direct ambient measurements of the CCN activity of smoke plumes are rare (Lawson et al., 2015) and more measurements are useful in assessing the validity of climate models. A previous preliminary study of the $\mathrm{CCN}$ activity of savannah fires in the northern Australian early dry season reported moderately hygroscopic BBA (Fedele, 2015), speculating that the aerosol is mostly made up of aged biomass burning particles with a coating of secondary organic aerosol. While these measurements took place over a short period, there was a discernable slight increase in the hygroscopicity of BBA during the day. Diurnal patterns in hygroscopicity have been observed in boreal environments (Paramonov et al., 2013) and in the southeast United States (Cerully et al., 2015), attributing increases in daytime hygroscopicity to the photochemical oxidation of organic aerosol.

Some studies suggest that the impact of composition, and therefore changes in BBA hygroscopicity due to photochemical aging, on $\mathrm{CCN}$ concentrations is much lower than the impact from the aerosol size distribution (Dusek et al., 2006; Petters et al., 2009; Spracklen et al., 2011). Under this assumption, changes to the activation diameter resulting from a change in hygroscopicity are less important than the size distribution of the BBA. Other studies have shown that while this is true for moderately and strongly hygroscopic particles, cloud droplet number concentrations are moderately sensitive to weakly hygroscopic particles (Reutter et al., 2009; Sánchez Gácita et al., 2017).

Smoke from biomass burning can be transported over intercontinental distances and can reach the upper levels of the atmosphere (Andreae et al., 2001; Dirksen et al., 2009). Aircraft measurements during the early and late dry season in northern Australia, however, suggest that smoke from fires in this region is contained within the planetary boundary layer (Ristovski et al., 2010; Kondo et al., 2003). Trade winds collect and carry this smoke northwest over northern Australia, the Timor Sea and the tropical warm pool. Cloud albedo is more sensitive to aerosol concentrations in pristine environments (Twomey, 1991). The biomass burning that occurs during the dry season is the dominant source of particles in northern Australia, and is therefore likely to influence aerosol-cloud interactions over the tropical warm pool in the Timor Sea.

This paper presents a comprehensive data set of the particle size, chemical composition, hygroscopicity and CCN properties of BBA generated from fires in the dry season in 


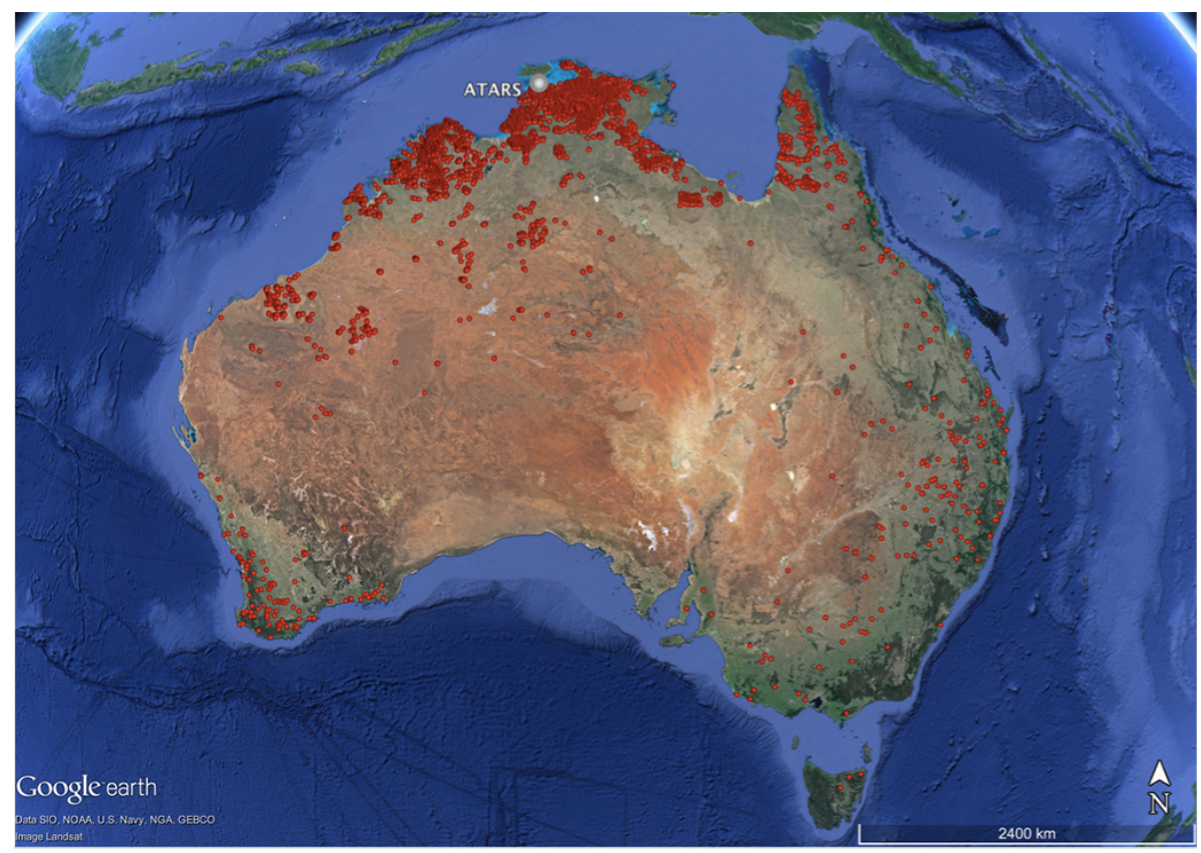

Figure 1. The total number of detected hotspots (confidence that hotspot is fire $>50 \%$ ) between 30 May and 1 July 2014 in Australia.

this region. The impact of BBA size and hygroscopicity on $\mathrm{CCN}$ activation is discussed in detail. These parameters will be useful in climate models to assess the magnitude of climate forcing by BBA in aerosol-cloud interactions.

\section{Experimental design}

Sampling took place at the Australian Tropical Atmospheric Research Station (ATARS; $12^{\circ} 14^{\prime} 56.6^{\prime \prime} \mathrm{S}, 131^{\circ} 02^{\prime} 40.8^{\prime \prime} \mathrm{E}$ ), Gunn Point, in the Northern Territory of Australia as a part of the Savannah Fires in the Early Dry season (SAFIRED) campaign (Mallet et al., 2016). The research station is located near the tip of a small peninsula with close proximity to the Timor Sea and Tiwi Islands. The territorial capital, Darwin, lies $20 \mathrm{~km}$ to the southwest of the station. Savannah vegetation with scarce human settlements transitions over hundreds of kilometres to the south into the desert regions of central Australia. Sampling for the SAFIRED campaign occurred in June 2014 at ATARS. This period is the early dry season in this region, where strategic small-scale controlled burns are performed in order to reduce the frequency and intensities of fires in the late dry season in October and November. Despite sampling occurring during winter, daily temperatures can reach well above $30^{\circ} \mathrm{C}$ such that accidental and natural fires can also occur. Throughout the sampling period, thousands of fires were observed in northern Australia. This led to strong biomass burning signatures detected at the station, with numerous instances of very intense BBA events from both distant and close fires. A full overview of the cam- paign, including meteorological, gaseous and aerosol measurements, is presented in Mallet et al. (2016).

Sentinel Hotspots, an Australian national bushfire monitoring system, was used to investigate the number of daily fires in the region. Sentinel uses data from the MODIS (Moderate-resolution Imaging Spectroradiometer) sensors onboard the Terra and Aqua NASA satellites and the VIIRS (Visible Infrared Imaging Radiometer Suite) sensor onboard the NASA/NOAA Suomi NPP satellite. These satellites fly over northern Australia once per day between 11:00 and 15:00 local time. Although fire locations are therefore limited to those that are burning during these times, Sentinel is still useful in providing information on the spread and number of fires burning in the region. Over the sampling period of this study, over 28000 hotspots (with a detection confidence of at least $50 \%$ ) were detected, with more than half of these occurring within $400 \mathrm{~km}$ of ATARS (see Fig. 1). For this study, the total number of observed fires within 10 and $20 \mathrm{~km}$ of ATARS was also calculated (Fig. 2b) for a qualitative assessment of how the smoke from these fires can affect cloud condensation nuclei concentrations.

\subsection{Instrumentation}

Aerosol size, concentration, composition, hygroscopicity and $\mathrm{CCN}$ concentration measurements were taken to characterise BBA water uptake and its potential impact on cloud formation. Ambient aerosol was sampled through an automated regenerating aerosol diffusion dryer to condition the intake to below $40 \%$ relative humidity. $\mathrm{PM}_{1}$ filters were collected on a TAPI 602 Beta Plus particle measurement system 
(BAM) for an analysis of EC and OC. A scanning mobility particle analyzer (SMPS) made up of a TSI 3071 electrostatic classifier and TSI 3772 condensation particle counter (CPC) was used to determine the particle size distributions and number concentrations between 14 and $650 \mathrm{~nm}$ with a 5 min averaging time. A cloud condensation nuclei counter (CCNC) was used to measure total cloud droplet concentrations at a supersaturation of $0.5 \%$ every $10 \mathrm{~s}$. A hygroscopicity tandem differential mobility analyser (H-TDMA) alternated measurement of the hygroscopic growth factor (HGF; $\left.D / D_{\mathrm{d}}\right)$ of ambient 50 and $150 \mathrm{~nm}$ size-selected particles exposed to a relative humidity of $90 \%$ (Johnson et al., 2004).

An Aerodyne compact time-of-flight aerosol mass spectrometer (cToF-AMS) was used to determine the sizeresolved chemical composition of non-refractory sub-micron aerosol. A full discussion on the cToF-AMS analysis of the composition of bulk $\mathrm{PM}_{1}$ aerosol can be found in Milic et al. (2016). Briefly, in order to account for fragmentation table issues during periods of high signals in which some sulfate species were misattributed to organics, the high-resolution AMS analysis toolkit PIKA was used to separate organic and sulfate signals. Data for the analysis of the size-resolved chemical composition within PIKA were not recorded during the sampling period and therefore the standard AMS analysis toolkit, Squirrel, was used with unit mass resolution. In order to account for fragmentation table issues related to the incorrect assignment of organic and sulfate species, the sizeresolved mass concentrations for each species were scaled by the ratio of the mass concentrations reported by the PIKA analysis to the integrated mass concentrations reported by Squirrel. The size-resolved composition revealed that inorganic ammonium and sulfate species made up a greater contribution of larger particles than in smaller particles (Fig. S1). The composition of particles between 100 and $200 \mathrm{~nm}$ (aerodynamic diameter) was therefore used in this study as this size range is more representative of aerosols at the $\mathrm{CCN}$ activation diameter. This is further discussed in Sect. 3.3.

\subsection{Analysis}

Total particle number concentrations ( $\mathrm{PNc}$ ) were calculated by integrating the size distributions measured by the SMPS. The activation ratio of $\mathrm{BBA}$ as $\mathrm{CCN}$ at $0.5 \%$ supersaturation was calculated by dividing the $\mathrm{CCNc}$ by the PNc. Apparent activation diameters were calculated by a step-wise integration of the particle size distribution from the maximum size bin towards the lower size bins until the total number of particles exceeded the total number of $\mathrm{CCN}$, as per

$$
\mathrm{CCNc}=\int_{\substack{\text { Activation } \\ \text { diameter }}}^{\substack{\text { Upper } \\ \text { diameter }}} \mathrm{d} N / \mathrm{d} \log D_{\mathrm{p}} \cdot \mathrm{d} D_{\mathrm{p}},
$$

where $\mathrm{CCNc}$ is the total cloud condensation nuclei concentration, $N$ is the particle number concentration for each size bin, $D_{\mathrm{p}}$ is the particle diameter, the upper diameter is the largest size measured by the SMPS $(650 \mathrm{~nm})$ and the activation diameter is the size at which the particles activate to cloud droplets. To calculate the precise activation diameter, a linear fit $\left(R^{2}>0.98\right)$ between the cumulative particle number concentrations and the diameter was applied across 11 size bins centred on the bin in which the activation diameter falls. The uncertainty in the activation diameters was calculated assuming a maximum uncertainty in the $\mathrm{CCN}$ concentrations of $\pm 10 \%$ and was typically of the order of $7 \mathrm{~nm}$. The extremely vast majority of particles were observed around $100 \mathrm{~nm}$ and, on average, only $0.07 \%$ of the number of particles measured by the SMPS were between 600 and $650 \mathrm{~nm}$. The influence of particles larger than $650 \mathrm{~nm}$ that were not measured by the SMPS was therefore negligible on the calculation of CCNc.

The apparent activation diameters were then used to calculate the average effective hygroscopicity parameter, $\kappa$, for each SMPS scan following $\kappa$-Köhler theory (Petters and Kreidenweis, 2007; Petters et al., 2009). According to this theory, the supersaturation required to achieve a particular droplet diameter for any given particle can be determined using:

$S(D)=\frac{D^{3}-D_{\mathrm{d}}^{3}}{D^{3}-D_{\mathrm{d}}^{3}(1-\kappa)} \exp \left(\frac{4 \sigma_{\mathrm{s} / \mathrm{a}} M_{\mathrm{w}}}{\operatorname{RT} \rho_{\mathrm{w}} D}\right)$,

where $S$ is the supersaturation, $D$ is the droplet diameter, $D_{\mathrm{d}}$ is the dry particle diameter, $\kappa$ is the hygroscopicity parameter, $\sigma_{\mathrm{s} / \mathrm{a}}$ is the surface tension of the interface between the solution and air (typically $0.072 \mathrm{~J} \mathrm{~m}^{-2}$ as pure water is assumed), $M_{\mathrm{w}}$ is the molecular weight of water, $R$ is the universal gas constant, $T$ is the temperature (taken as $308 \pm 3 \mathrm{~K}$ in this study) and $\rho_{\mathrm{w}}$ is the density of water. For a range of $D_{\mathrm{d}}$ values, $\kappa$ and $D$ values were iteratively varied until the maximum of the $\kappa$-Köhler curve was equal to $0.5 \%$, the supersaturation used in the CCNC. A relationship was then found between $\kappa$ and $D_{\mathrm{d}}$ for the range of 45 up to $160 \mathrm{~nm}$ (Fig. S2). This relationship was then applied to the calculated activation diameters over the sampling period to calculate the BBA $\kappa$ values. The uncertainty in the activation diameter of $7 \mathrm{~nm}$ led to uncertainties in $\kappa$ of $\sim 0.05$ for activation diameters between 60 and $80 \mathrm{~nm}, \sim 0.01$ for activation diameters between 80 and $100 \mathrm{~nm}$, and less than 0.01 for activation diameters above $100 \mathrm{~nm}$.

The value of $\kappa$ derived from the CCNC and SMPS is the average for all particle sizes. If there is not a uniform composition, this value cannot necessarily be applied to all sizes of BBA. All H-TDMA data were inverted using the TDMAinv algorithm (Gysel et al., 2009) and HGF distributions were kelvin-corrected for comparison between 50 and $150 \mathrm{~nm}$ particles at $90 \%$ relative humidity. Equation (2) was then also applied to the kelvin-corrected HGF distributions, thereby providing distributions of $\kappa$. This also provides an insight into the mixing state of the BBA, which cannot be 
determined from the CCNC and SMPS measurements in this study.

When the surface tension of pure water is assumed, $\kappa$ is regarded as the "effective hygroscopicity parameter", which accounts for changes in water activity due to the solute as well as any surface tension effects (Petters and Kreidenweis, 2007; Rose et al., 2010; Pöschl et al., 2009). The effective hygroscopicity parameter is therefore an indication of all compositional effects of an aerosol particle on water uptake. To distinguish the potential effects of surface tension, values of 0.052 and $0.0683 \mathrm{~J} \mathrm{~m}^{-2}$ were also applied. Mircea et al. (2005) suggest that the surface tension at the liquid-air interface of a particle depends on the concentration of carbon. The value $0.052 \mathrm{~J} \mathrm{~m}^{-2}$ represents a lower limit, while a surface tension of $0.0683 \mathrm{~J} \mathrm{~m}^{-2}$ has been observed for prescribed biomass burning particulate matter in wooded areas in the USA (Asa-Awuku et al., 2008). The impact of surface tension is discussed further in Sect. 3.5.

The overall hygroscopicity of any given particle can be determined by the volume fraction and hygroscopicity of each constituent under the Zdanovskii, Stokes and Robinson (ZSR) assumption (Chen et al., 1973; Stokes and Robinson, 1966):

$\kappa=\sum_{i} \varepsilon_{i} \kappa_{i}$,

where $\kappa$ is the overall hygroscopicity and $\varepsilon_{i}$ and $\kappa_{i}$ are the volume fractions and hygroscopicities of each constituent, respectively. A modelled $\kappa$ was constructed to determine the influence of diurnal changes in organic and inorganic volume fractions, where $\kappa_{\text {total }}=\varepsilon_{\text {org }} \kappa_{\text {org }}+\varepsilon_{\mathrm{EC}} \kappa_{\mathrm{EC}}+$ $\varepsilon_{\text {inorganic }} \kappa_{\text {inorganic }}$, following the ZSR assumption. The $12 \mathrm{~h}$ $\mathrm{PM}_{1}$ BAM filters sampled from 07:00 until 19:00 and from 19:00 until 07:00 each day showed no difference in the ratio of $\mathrm{EC}$ to $(\mathrm{OC}+\mathrm{EC})$, and therefore a constant mass fraction $\left(\mathrm{EC} /(\mathrm{EC}+\mathrm{OC})\right.$ of $10 \%$ was applied. $\varepsilon_{\mathrm{org}}, \varepsilon_{\mathrm{EC}}$ and $\varepsilon_{\text {inorganic }}$ were calculated using the size-resolved mass concentrations reported by the cToF-AMS and assumed densities of $1.4 \mathrm{~g} \mathrm{~cm}^{-3}$ (Levin et al., 2014), $1.8 \mathrm{~g} \mathrm{~cm}^{-3}$ (Bond and Bergstrom, 2006) and $1.8 \mathrm{~g} \mathrm{~cm}^{-3}$ (Levin et al., 2014), respectively. $\kappa_{\text {inorganic }}$ and $\kappa_{\mathrm{EC}}$ were taken as 0.60 (Bougiatioti et al., 2016) and 0 (Petters and Kreidenweis, 2007), respectively. The contribution of inorganics in this study was taken from the reported masses of sulfate, nitrate and ammonium species. During the period considered for this model, other inorganic species such as potassium, a marker for biomass burning, only made up a small and constant contribution to the total mass and were therefore not considered. A night (18:00 until 07:00) value and a day value of $\kappa_{\text {org }}$ were varied in the applied model in order to investigate any potential changes in organic hygroscopicity due to photochemistry.

$\mathrm{CCN}$ concentrations were calculated in order to test prediction of CCN concentrations using aerosol composition and size distribution in this region. Activation diameters were derived from various hygroscopicity parameters and, again

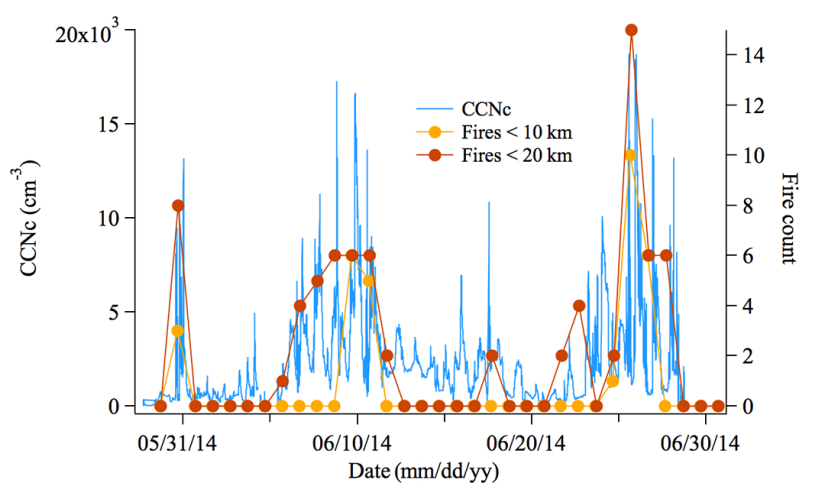

Figure 2. The time series of total cloud condensation nuclei concentrations $(\mathrm{CCNc})$ at $0.5 \%$ supersaturation and the total number of satellite-observed fires within $10 \mathrm{~km}$ (yellow) and $20 \mathrm{~km}$ (red) of the sampling location.

using Eq. (1), the size distribution was integrated step-wise from the upper size-limited measured in the SMPS until the activation diameter was reached. The same process used to calculate the precise activation diameters earlier was used to calculate the precise $\mathrm{CCN}$ concentrations. This process was carried out for the modelled hygroscopicity from the sizeresolved cToF-AMS data, the measured hygroscopicity distribution from the H-TDMA and various constant hygroscopicity values. The constant values selected were $0.05,0.1,0.2$ and 0.3 , as well as day and night values of 0.071 and 0.035 , respectively; 0.05 represents the campaign average effective hygroscopicity. The day and night values represent the campaign average values obtained from the SMPS-CCNC measurements. The values of 0.1 and 0.2 represent commonly observed hygroscopicities for BBA in other regions and in laboratory measurements (Engelhart et al., 2012). The global mean values of $\kappa$ have been estimated to be $0.27 \pm 0.21$ for continental aerosols (Pringle et al., 2010). It has been suggested that it is suitable to assume this continental average $(\kappa \sim 0.3)$ to make first-order predictions of $\mathrm{CCN}$ activity (Rose et al., 2011). Modelling CCN concentrations using these methods and assumed hygroscopicity values will verify whether such values are suitable in predicting CCN activity in regions like northern Australia.

In order to investigate the $\mathrm{CCN}$ activity of BBA, 4 days of unpolluted and coastal conditions (19-22 June 2014) were removed from the majority of the analysis. Furthermore, the SMPS was only operational from 4 June 2014. Analysis of $\mathrm{CCNc}$, PNc, activation ratios, median particle diameters, apparent activation diameters and the average effective hygroscopicity parameters is therefore only presented for data collected after this date. 

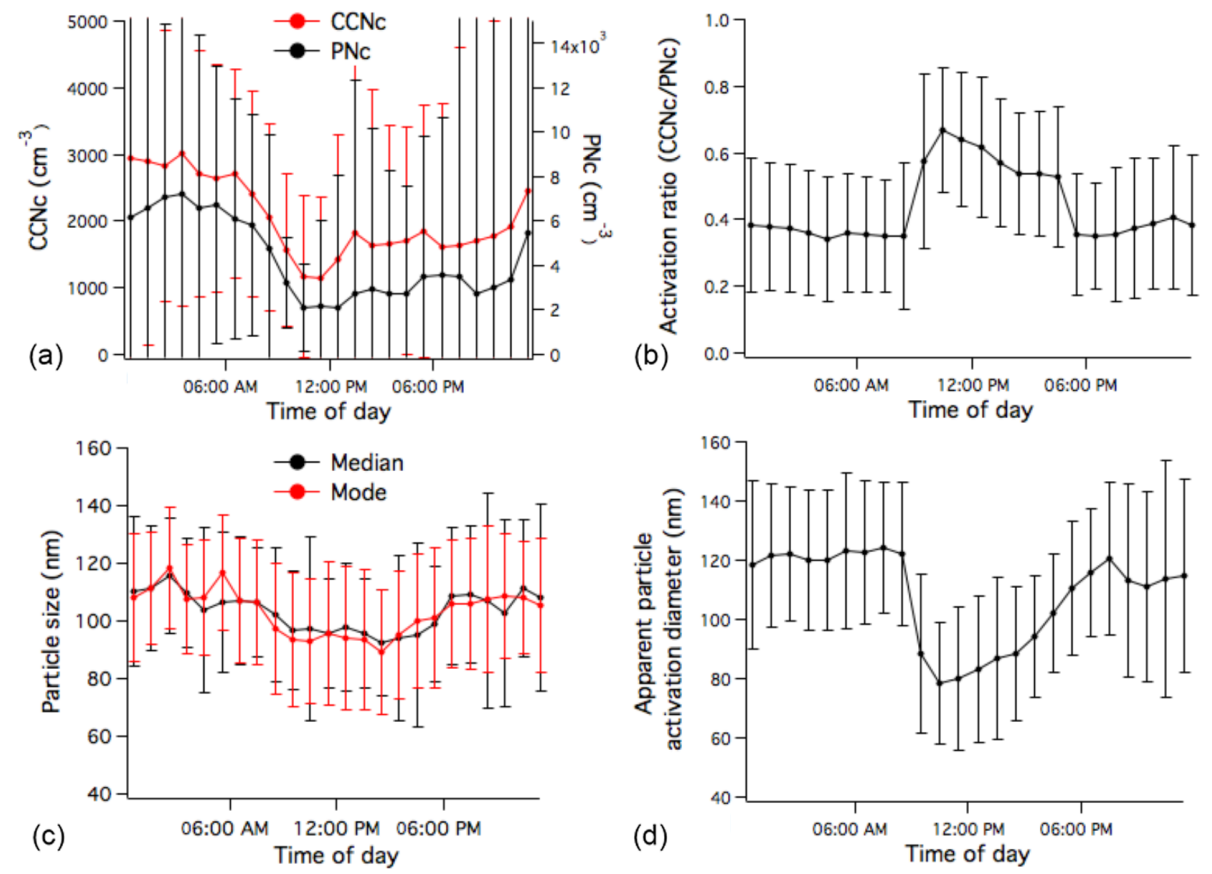

Figure 3. The diurnal trends of (a) the total cloud condensation nuclei concentration (CCNc) and particle number concentration (PNc), (b) the activation ratio at $0.5 \%$ supersaturation, (c) the median and mode of the particle size distribution, and (d) the apparent activation diameter. All reported values are the median of the hourly averaged data for the sampling period and the error bars represent the standard deviation.

\section{Results and discussion}

\subsection{BBA contribution to $\mathrm{CCN}$}

Figure 2 shows the CCN concentrations (supersaturation $0.5 \%$ ) measured at the ATARS over the campaign sampling period in June 2014 as well as the frequency of fires that were observed via satellite hotspots each day within 10 and $20 \mathrm{~km}$ of the station. Air mass back trajectories were typically from the southeast, as were the locations of the fires (Mallet et al., 2016). These back trajectories revealed that the air masses did not pass over Darwin or any close industrial sites, ruling out the likelihood of an urban influence on CCN concentrations. The period between 19 and 23 June was characterized by relatively low $\mathrm{CCN}$ concentrations due to air originating from the coastal waters of eastern Australia, which passed over minimal continental area before arriving at the ATARS. As already mentioned, these dates were subsequently excluded from the data analysis as the focus of this study was on the impact of BBA on CCN. The highest PNc and $\mathrm{CCN}$ concentrations were associated with large biomass burning events. PNc concentrations of up to $400000 \mathrm{~cm}^{-3}$ and $\mathrm{CCN}$ concentrations of up to $19000 \mathrm{CCN} \mathrm{cm}^{-3}$ were observed during these periods.

Although the PNc and $\mathrm{CCN}$ concentrations were highest during BBA events, these periods were characterized by the lowest hygroscopicity and activation ratios (ratio of $\mathrm{CCNc}$ to PNc as low as $4 \%$ ). This is further discussed in
Sect. 3.3. Activation ratios typically varied between 30 and $80 \%$, corresponding to $\mathrm{CCN}$ concentrations between 1500 and $6000 \mathrm{~cm}^{-3}$. This contrasts with observed activation ratios of over $80 \%$ in BBA from dry season savannah fires in tropical southern Africa during the SAFARI 2000 campaign (Ross et al., 2003), despite lower supersaturations of $\sim 0.3 \%$. The size distributions of BBA observed during SAFIRED had a count median diameter of $107 \pm 25 \mathrm{~nm}$, while the median diameters were typically above $150 \mathrm{~nm}$ in the SAFARI 2000 campaign, which could explain the lower activation ratios observed here. The size distributions observed in this study were typically smaller than those observed in aged and regional BBA on other continents (Reid et al., 2005). When particles are smaller, the critical diameter for cloud droplet formation becomes more important. It is therefore crucial to investigate the impact of composition on the activation diameter, and thus $\mathrm{CCN}$ concentrations.

\subsection{Diurnal trends in BBA}

Diurnal patterns in the BBA PNc, $\mathrm{CCNc}$, size and activation ratio and activation diameter are shown in Fig. 3. For most of the campaign, particle size distributions were unimodal and therefore the median and mode of these distributions are used here to represent the particle size. The highest concentrations of $\mathrm{CCN}$ were observed during the night, when they were also the most variable (Fig. 3a). This is likely a result of prescribed burns occurring later in the day or evening as 

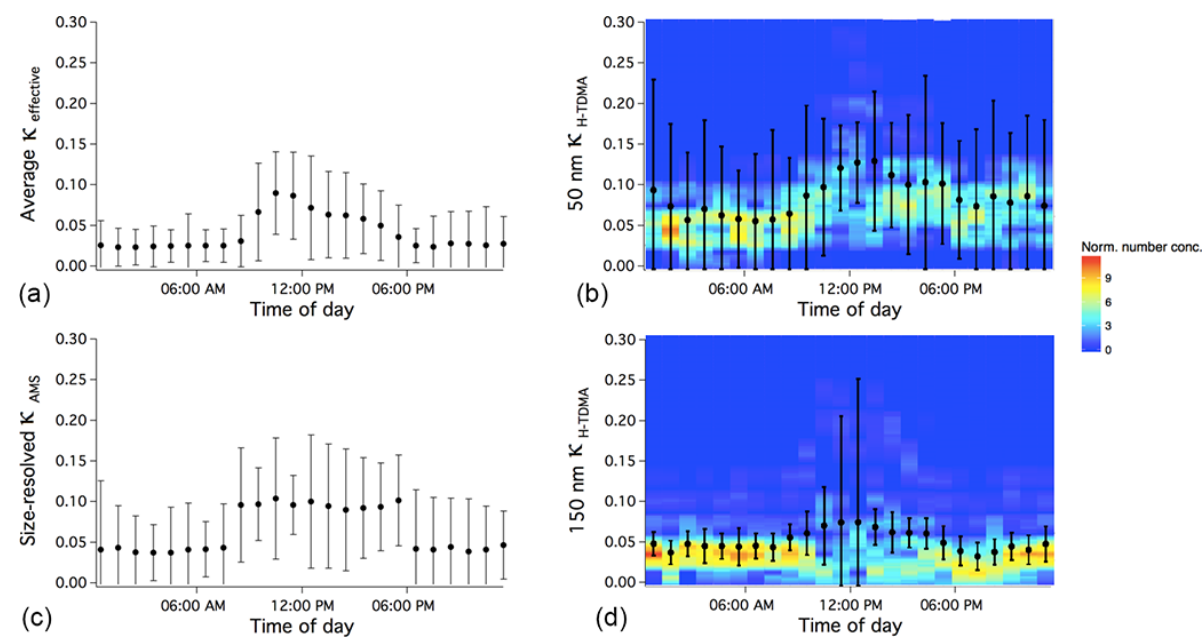

Figure 4. The diurnal trends of (a) the CCNC-derived effective hygroscopicity parameter, (b) the H-TDMA-derived kelvin-corrected hygroscopicity distributions of $50 \mathrm{~nm}$ particles, (c) the AMS-derived hygroscopicity parameter for aerodynamic diameters between 100 and $200 \mathrm{~nm}$, assuming $\kappa_{\text {org }}$ of 0.02 and 0.08 during the night and day, respectively, and (d) the H-TDMA-derived kelvin-corrected hygroscopicity distributions of $150 \mathrm{~nm}$ particles. The black dots in (b) and (d) represent the hourly median hygroscopicity values and the error bars represent the standard deviation.

well as a lower inversion layer during the night. Interestingly, the activation ratio also follows a distinct diurnal trend with $\sim 40 \pm 20 \%$ of BBA acting as $\mathrm{CCN}$ at $0.5 \%$ supersaturation during the night and $\sim 60 \pm 20 \%$ during the day (Fig. 3b). Smaller particles were typically seen during the day than during the night (Fig. 3c), indicating that it was the change in the particle activation diameter (Fig. 3d) that was responsible for this increase in daytime activation ratios. The decrease in the particle size could possibly be explained by changes in combustion (Carrico et al., 2016) of vegetation across the day, with more flaming, rather than smoldering, conditions expected to be favoured during daylight hours. Without more information on the exact location, fuel type and combustion conditions, however, it is difficult to make conclusions about this.

The hygroscopicity of BBA derived from the size-resolved AMS, CCNC/SMPS and the H-TDMA followed a distinct diurnal trend (Fig. 4). The CCNC-derived hygroscopicity (Fig. 4a) during the night-time (defined as 18:00 until 07:00 local time) was generally very stable and constant over the sampling period at $0.03 \pm 0.03$. Daytime hygroscopicity (07:00 until 18:00) was typically higher with much more variability at $0.07 \pm 0.05$. H-TDMA-derived hygroscopicities for $150 \mathrm{~nm}$ diameter particles (Fig. 4d) agreed very well with these values, although a much higher variability was observed around noon. The hygroscopicity distributions of $50 \mathrm{~nm}$ diameter particles followed a similar trend but were, interestingly, slightly higher than the $150 \mathrm{~nm}$ distributions. The variability in hygroscopicity for $50 \mathrm{~nm}$ diameter particles is much greater than for $150 \mathrm{~nm}$ particles, due to lower concentrations at $50 \mathrm{~nm}$. Hygroscopicity distributions for both 50 and $150 \mathrm{~nm}$ aerosols during the night indicate a strong internal mixture of very weak hygroscopic BBA, and during the day an increase and broadening of the hygroscopicity mode, suggesting an external mixture of slightly more hygroscopic particles. The size-resolved AMS hygroscopicity values were calculated assuming $\kappa_{\text {org }}$ of 0.02 and 0.08 during the night and day, respectively. The organic volume fraction was invariable (see Sect. 3.3); therefore, the increase and decrease at sunrise and sunset, respectively, are driven by the choice of night and day organic hygroscopicity values. These values were selected as they gave the best agreement between the modelled and measured CCN concentrations, which is discussed further in Sect. 3.4.

Literature on the diurnal variability in BBA hygroscopicity is rare. Diurnal and afternoon averages of $\kappa$ for BBA in the Amazonian dry season have been reported as 0.048 and 0.072, respectively (Sánchez Gácita et al., 2017), consistent with the results presented here. A short study (Fedele, 2015) carried out in 2010 at the ATARS also reported $\kappa$ values in the early dry season over a period of 2 weeks. They showed $\kappa$ values mostly between 0.05 and 0.1 for supersaturations of $0.38,0.68$ and $0.96 \%$, with the higher values generally occurring during the day. They directly measured the critical diameter and used an approximation presented in Petters and Kreidenweis (2007) to calculate $\kappa$. This approximation is more appropriate for $\kappa$ values over 0.2 , which means that the reported values between 0.05 and 0.1 were slightly overestimated and would likely be more in line with the BBA hygroscopicity observed in this study. Although a detailed chemical analysis was not done during that study, these similar values of $\kappa$ suggest that these observations could be representative of early dry season fires in this region. 


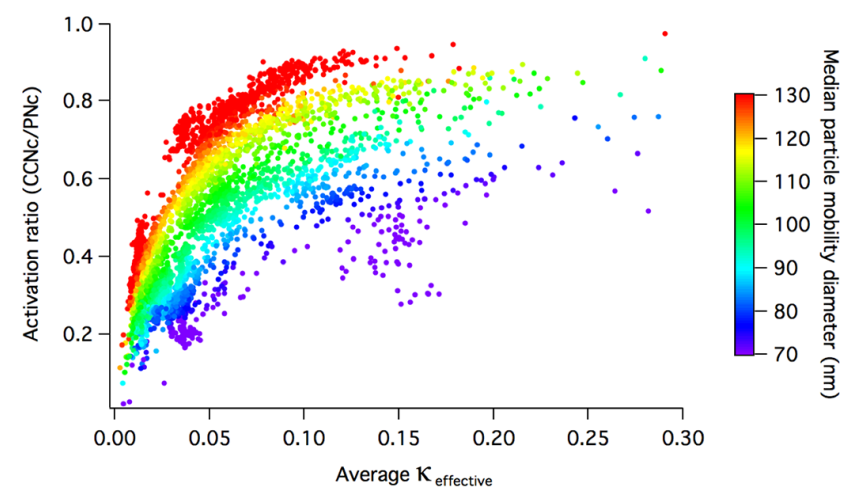

Figure 5. The activation ratio $(\mathrm{CCNc} / \mathrm{PNc})$ as a function of the effective hygroscopicity parameter, $\kappa$. The colours represent the median particle mobility diameter.

\subsection{BBA composition}

The activation ratio as a function of the effective hygroscopicity parameter, $\kappa$, as calculated from Eqs. (1) and (2), with colours indicating the median particle mobility diameter, is displayed in Fig. 5. This figure clearly demonstrates that both the size and composition of the BBA can have a significant effect on CCN activation. For example, with a constant particle size increases the $\mathrm{CCN}$ activation ratio from below 20 to above $80 \%$. For a constant $\kappa$ of 0.05 and an increase in the particle median diameter from 60 up to $140 \mathrm{~nm}$, the $\mathrm{CCN}$ activation ratio increases by approximately $50 \%$. The effect of composition appears to have less of an influence at higher hygroscopicities, with the size being the determining factor in $\mathrm{CCN}$ activation above a $\kappa$ of 0.1 . For very weakly hygroscopic $(\kappa<0.05) \mathrm{BBA}$, the sensitivity of particle size was less prominent, with an activation ratio increase of $\sim 0.3 \% \mathrm{~nm}^{-1}$, compared to a $\sim 0.7 \% \mathrm{~nm}^{-1}$ increase when $\kappa>0.05$. These findings support the idea that cloud droplet number concentrations are sensitive to composition at low hygroscopicities (Reutter et al., 2009). Neglecting the effect of BBA composition in this case would lead to difficulties in appropriately quantifying $\mathrm{CCN}$ activation.

In order to understand the underlying causes of the variations in the hygroscopicity, the size-resolved chemical composition was investigated. For bulk $\mathrm{PM}_{1}$ composition, there was a distinct increase in the inorganic mass fractions during the day due to an enrichment of ammonium and sulfate species. The size-resolved composition, however, revealed that these inorganic species were more present on larger particles and had a $d_{\text {aerodynamic }}$ mode at approximately $350 \mathrm{~nm}$, while organics had a mode at approximately $250 \mathrm{~nm}$. This observation is consistent with other studies that show that smaller particles are more enriched with organics (Levin et al., 2014; Rose et al., 2011; Gunthe et al., 2009). As the influence of composition on CCN activation is irrelevant at larger sizes, it is important to investigate the composition at smaller sizes where the aerosol number is highest and the compo- sition can affect the activation diameter. The size-resolved composition revealed that, within the aerodynamic diameter size range of 100 to $200 \mathrm{~nm}$, organics were completely dominant and the organic volume fraction, $\varepsilon_{\text {org }}$, was invariable at approximately $90 \%$. At least some of the increase in the observed hygroscopicity, $\kappa$, and the inferred $\kappa_{\text {org }}$ is likely a result of the photochemical oxidation of the organics. The aging of biomass burning aerosol is discussed in further detail in Milic et al. (2016), where the fraction of $m / z 44$ to total organics measured by the AMS, a proxy for the degree of oxidation, was shown to increase steadily throughout the day. As shown in Fig. 4, the derived hygroscopicity values from the CCNc, SMPS and H-TDMA show a decrease in the hygroscopicity soon after the peak at midday. If the photochemical oxidation of organics were the sole contributor to the daytime increase in hygroscopicity, then it should be expected that the hygroscopicity would also increase steadily throughout the day (in the absence of a change in the mass fraction of inorganics). While there was no change in wind direction until later in the afternoon, the peak in hygroscopicity did correspond with the peak in wind speed (see Fig. S4 in the Supplement), although it is not apparent how or if a decrease in the wind speed could lead to a decrease in the hygroscopicity. A separate explanation could be related to the size-dependent composition of BBA. The size-resolved composition from the AMS across the range of 100-200 nm was selected due to the inefficient transmission of particles below $100 \mathrm{~nm}$. As shown in Fig. 3d, the apparent activation diameter during the day decreased to approximately $80 \mathrm{~nm}$. It could be that the composition between 100 and $200 \mathrm{~nm}$ is therefore not perfectly representative of the BBA at the activation diameter. Furthermore, the influence of other inorganics not considered in the model of hygroscopicity or the role of surface chemistry could be underestimated, leading to poor characterisation of hygroscopicity by bulk composition.

While it is likely that most of the BBA observed during the SAFIRED campaign had undergone some form of aging (physical or chemical), two events provided insight into the characteristics of extremely fresh BBA and are described in Mallet et al. (2016). During mid-afternoon on 25 June, grass and shrub fires were blazing $\sim 1 \mathrm{~km}$ southeast of the ATARS site. Wind directions during this period were very unstable and frequently altering between southeasterly and northeasterly. This resulted in the sampled air mass frequently changing from the "fresh" plume and more background-like conditions over the course of approximately $4 \mathrm{~h}$. During this time, CCN concentrations varied frequently between $\sim 2000$ and $\sim 19000 \mathrm{~cm}^{-3}$. The activation ratio, median particle size, activation diameter and hygroscopicity varied between 20 and $75 \%$; 80 and $110 \mathrm{~nm} ; 130$ and $80 \mathrm{~nm}$; and 0.02 and 0.1 , respectively (see Fig. 6). These fires continued to blaze into the evening, slowly advancing to within $1 \mathrm{~km}$ south of the ATARS site. Due to northeasterly winds, the air mass from this fire was not observed until approximately 22:00 that night, when winds became southerly. For the next $4 \mathrm{~h}, \mathrm{CCN}$ 


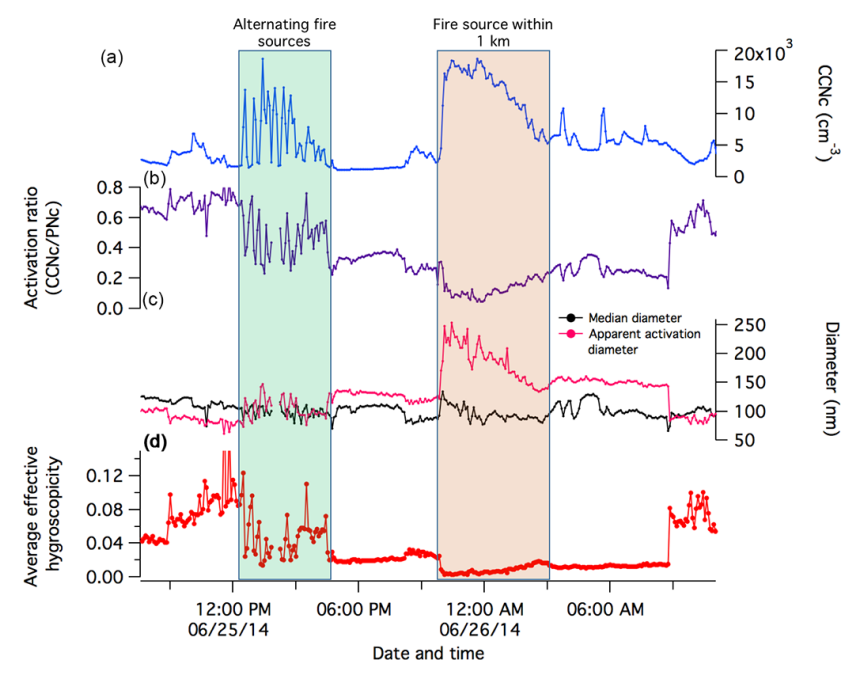

Figure 6. The $\mathrm{CCNc}$, activation ratio, median particle diameter, apparent activation diameter and average effective hygroscopicity parameter during two periods with close-proximity $(<1 \mathrm{~km})$ fires. The green shaded area indicates the period where the wind direction was periodically changing between southeasterly and northeasterly. The red shaded area indicates the period where emissions were from a grass fire burning less than $1 \mathrm{~km}$ from the sampling site.

concentrations peaked at $\sim 19000 \mathrm{~cm}^{-3}$, despite the activation ratio dropping to $4 \%$. The average effective hygroscopicity during this event dropped to 0.003 and slowly increased over the period of the fire to $\sim 0.02$. This led to a decrease in the apparent activation diameter from 250 to $150 \mathrm{~nm}$, subsequently increasing the $\mathrm{CCN}$ activation ratio to $25 \%$. Whether this is a result of a change in the burning conditions, fuel load or a combination of both is unclear. These events demonstrate the importance of $\mathrm{BB}$ as a source of $\mathrm{CCN}$, despite the relatively hydrophobic nature of BBA. Furthermore, in the absence of photochemical aging, the slight variation in BBA hygroscopicity during the night fire demonstrates the variability in CCN activation, even over the course of an individual fire.

The hygroscopicity of fresh and aged BBA has been studied extensively in laboratory smog chambers. Some studies have shown that the photochemical oxidation of organics in BBA leads to an increase in hygroscopicity (Carrico et al., 2010; Petters et al., 2009; Engelhart et al., 2012), while others suggest that the hygroscopicity converges from highly $(\kappa=0.6)$ or weakly $(\kappa=0.06)$ hygroscopic values to a value of approximately $0.2 \pm 0.1$ (Engelhart et al., 2012). The observation of the close-proximity fire event on the evening of 25 June (Fig. 6), as well as the diurnal trends in the calculated hygroscopicity parameter (Fig. 4), indicates that the composition of BBA during the night is characteristic of very weakly hygroscopic fresh BBA. The high frequency of fires during the early dry season in northern Australia likely results in the "regional haze" predominantly being composed of relatively fresh BBA with a very low hygroscopicity. The aging processes were observed to increase the hygroscopicity to $\sim 0.08 \pm 0.05$, which is the lower estimate of value suggested by Engelhart et al. (2012) and smaller than other studies investigating BBA (Bougiatioti et al., 2016). Whether the hygroscopicity would converge to higher values in the absence of frequent fires or as the smoke travels away from the continent is something that needs to be explored in future measurements.

\subsection{Validation of modelled CCN}

Detailed temporal-spatial measurements of CCN concentrations are difficult and therefore assumptions must be made about the size-resolved composition and water uptake for similar regions and sources. Many studies have attempted closure between composition, size and $\mathrm{CCN}$ concentrations in order to assess the validity of these assumptions (Rose et al., 2010). These studies typically agree that for most environments, where hygroscopicities are moderate, the size distribution and number concentration of particles are the determining factors of CCN concentrations (Dusek et al., 2006). Sánchez Gácita et al. (2017), however, showed that for Amazonian BBA (with measured $\kappa=0.04$ ), applying an assumed $\kappa$ of 0.20 resulted in a 26.6 to $54.3 \%$ overestimation of CCN concentrations. They suggest that $\kappa$ values recommended for continental and BBA are too high to describe $\mathrm{CCN}$ behaviour of Amazonian BBA. This is also the case for the SAFIRED campaign.

Figure 7 shows the normalised frequency distributions of the ratio of modelled and measured $\mathrm{CCN}$ concentrations for five different compositional scenarios, taking into account the time-dependent size distributions. The smoothed curves were obtained frequency distributions of these ratios, using Igor Pro's Multi-peak Fitting package. For a constant hygroscopicity of 0.20 , daytime concentrations were overestimated by 15 to $40 \%$, while night concentrations were overestimated by well over $100 \%$. A similar case is observed for hygroscopicities of 0.10 and 0.30 . For an assumed constant $\kappa$ of 0.05 , which represents the campaign average, the modelled CCN concentrations slightly underestimate the measured CCN concentrations during the day by less than $10 \%$ but overestimate the night $\mathrm{CCN}$ by $65 \%$. Using the day and night campaign averages of 0.071 and 0.035 , respectively, improved the night-time concentration to an overestimation of approximately $50 \%$. Using the time-dependent size-resolved AMS composition and assigning and $\kappa_{\text {org }}$ as 0.08 and 0.02 for day and night, respectively, also provides a good agreement between the estimated and measured daytime $\mathrm{CCN}$ concentrations, but it again overestimates the night concentrations by $70 \%$. H-TDMA hygroscopicity distributions showed that the night was predominantly characterised by an internal mixture, suggesting that the disagreement between modelled and measured $\mathrm{CCN}$ is due to is due to variability in fuel or burning conditions of the fires and/or nighttime aging. The modelled $\mathrm{CCN}$ concentrations from both 

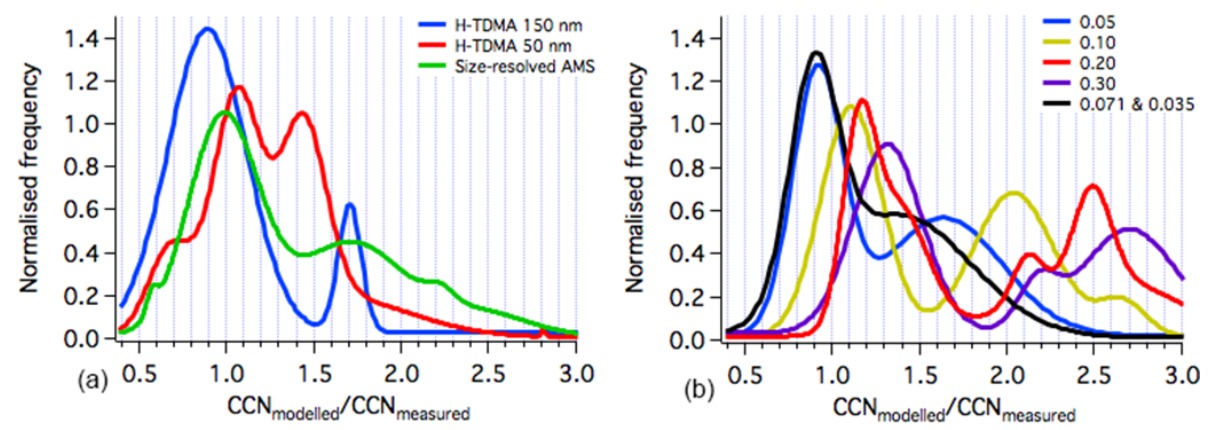

Figure 7. The normalised probability density functions for the frequency of the ratio of the modelled and measured CCN concentrations based on (a) the 150 and $50 \mathrm{~nm}$ H-TDMA-derived hygroscopicities and size-resolved cToF-AMS composition and (b) the campaign average hygroscopicity, $\kappa=0.05$; typical $\mathrm{BB}$ hygroscopicities of 0.1 and 0.2 ; the continental average hygroscopicity of 0.3 ; and the day and night average effective hygroscopicity values of 0.071 and 0.035 , respectively.

the 50 and $150 \mathrm{~nm}$ H-TDMA were within $10 \%$ during the day, but there were also overestimations of between 45 and $70 \%$, respectively. The time resolution of the H-TDMA limited the number of $\mathrm{CCN}$ model calculations that could be done, which introduced more potential bias for individual periods where the agreement between the measured and modelled CCN was worse (or better). The difficulty in sufficiently modelling night-time CCN concentrations highlights the need for further composition measurements of fresh BBA in this region.

\subsection{Effect of surface tension}

The $\kappa$ values reported in this study represent the effective hygroscopicity parameter, which accounts for all compositional effects on aerosol water uptake (i.e. solubility of components and the reduction in surface tension to their presence). This study has shown that the effective hygroscopicity parameter increases during daylight hours, leading to speculation that this is caused by the photochemical oxidation of organics. Although surface tension measurements were not performed, using a value observed in a previous BB study of $0.0638 \mathrm{~J} \mathrm{~m}^{-2}$ (Asa-Awuku et al., 2008) in the $\kappa$-Köhler equation shows only a slight decrease in hygroscopicity compared to using the surface tension of pure water (Figs. S2 and S3). This suggests that it is the solubility, rather than the reduction of surface tension, of the organics and inorganics present in the BBA that is responsible for the water uptake. On the other hand, an assumed lower estimate surface tension of $0.052 \mathrm{~J} \mathrm{~m}^{-2}$ (Mircea et al., 2005) during the day could explain the increase in $\mathrm{CCN}$ activation. Although models generally use the effective hygroscopicity parameter (Pringle et al., 2010) due to the ease of using a single parameter, a better understanding of the precise mechanisms that facilitate the uptake of water onto potential cloud droplets is needed (Noziere, 2016).

\section{Conclusions}

Measurements at ATARS showed a strong link between the frequency of early dry season fires and the concentrations of $\mathrm{CCN}$, indicating that these fires are an important source of $\mathrm{CCN}$ in northern Australia. The aerosol size distribution was typically unimodal with a median diameter of $107 \mathrm{~nm}$ and the BBA was weakly hygroscopic and predominately internally mixed. These conditions meant that both the composition and size were important in determining the $\mathrm{CCN}$ activation of the BBA. A distinct diurnal trend in the ratio of activated cloud condensation nuclei at $0.5 \%$ supersaturation and particle number was observed, with $\sim 40 \pm 20 \%$ of BBA acting as $\mathrm{CCN}$ during the night and $\sim 60 \pm 20 \%$ during the day. This increase in CCN activity corresponded with an increase in the hygroscopicity from $0.04 \pm 0.03$ to $0.07 \pm 0.05$. This was likely due to the daytime photochemical oxidation of organic compounds within BBA, although other factors such as changes in sub-100 nm inorganic contributions or surface chemistry were likely also contributing factors. While not investigated in this study, this smoke has the potential to penetrate into the upper levels of the troposphere, particularly as the dry season progresses, and it also flows over the Timor Sea, where change in cloud albedo and lifetime is likely to be sensitive to CCN concentration changes. In the case of northern Australian dry season fires, assuming typical continental hygroscopicities of $0.10,0.20$ and 0.30 led to CCN overestimates of 10 to $30 \%$ during the day and 100 to over $150 \%$ during the night. It is therefore important that the $\mathrm{CCN}$ activation be better modelled.

BBA related CCN concentrations are likely to be further enhanced throughout the dry season as temperatures increase and there are more frequent fires. Long-term monitoring or future measurements later in the dry season would allow a more detailed analysis into the seasonal relationship between fire frequency, intensity and CCN. Other aerosolcloud interactions are likely to change as the season progresses. Higher solar radiation and relative humidity during 
the late dry season lead to the formation of pyro-cumulous clouds and higher rainfall in comparison to the early dry season (Bowman et al., 2007). Long-term measurements could also be further integrated in with satellite data, such as the burned-area product measured by the MODIS sensors. While the number of fires detected in this study is useful for a qualitative assessment of the impact of fires on CCN concentrations, the area burned is likely to be a more quantitative proxy for BBA emissions.

Concurrent aircraft measurements would be required to investigate the penetration and evolution of smoke into upper levels of the troposphere. Characterising the presence of smoke within, below and above clouds is required to fully understand the vertical radiative effect of these fires. The southeasterly trade winds carry this smoke over waters in the Indian and western Pacific oceans known as the tropical warm pool. Measurements in Indonesia or on a ship in the Timor Sea would therefore also be useful in determining the long-range transport and evolution of the smoke. Furthermore, a mobile sampling chamber positioned downwind of prescribed burns that occur in this region, both during the day and night, would be beneficial in understanding the variability in the composition of freshly emitted BBA.

Data availability. Raw data are available upon request to the corresponding author (Branka Miljevic; b.miljevic@qut.edu.au).

\section{The Supplement related to this article is available online at doi:10.5194/acp-17-3605-2017-supplement.}

Author contributions. Marc Mallet wrote the manuscript, designed and conducted experimental work, and analysed and interpreted data. Luke Cravigan designed and conducted experimental work and contributed to writing the manuscript, data analysis and data interpretation. Andelija Milic analysed data and reviewed the manuscript. Joel Alroe designed experimental work, analysed data and reviewed the manuscript. Zoran Ristovski designed experimental work and reviewed the manuscript. Jason Ward designed and conducted experimental work. Melita Keywood led the SAFIRED campaign and reviewed the manuscript. Leah Williams contributed to the experimental work and reviewed the manuscript. Paul Selleck designed experimental work and analysed data. Branka Miljevic designed and conducted experimental work and reviewed the manuscript.

Competing interests. The authors declare that they have no conflict of interest
Acknowledgements. The authors would like to acknowledge and thank Brad Atkinson from the Australia Bureau of Meteorology for providing support at the research station.

Edited by: M. Petters

Reviewed by: two anonymous referees

\section{References}

Andersen, A. N., Cook, G. D., Corbett, L. K., Douglas, M. M., Eager, R. W., Russell-Smith, J., Setterfield, S. A., Williams, R. J., and Woinarski, J. C.: Fire frequency and biodiversity conservation in Australian tropical savannas: implications from the Kapalga fire experiment, Austral. Ecology, 30, 155-167, 2005.

Andreae, M., Artaxo, P., Fischer, H., Freitas, S., Grégoire, J. M., Hansel, A., Hoor, P., Kormann, R., Krejci, R., and Lange, L.: Transport of biomass burning smoke to the upper troposphere by deep convection in the equatorial region, Geophys. Res. Lett., 28, 951-954, 2001.

Asa-Awuku, A., Sullivan, A. P., Hennigan, C. J., Weber, R. J., and Nenes, A.: Investigation of molar volume and surfactant characteristics of water-soluble organic compounds in biomass burning aerosol, Atmos. Chem. Phys., 8, 799-812, doi:10.5194/acp8-799-2008, 2008.

Bond, T. C. and Bergstrom, R. W.: Light absorption by carbonaceous particles: An investigative review, Aerosol Sci. Tech., 40, 27-67, 2006

Bougiatioti, A., Bezantakos, S., Stavroulas, I., Kalivitis, N., Kokkalis, P., Biskos, G., Mihalopoulos, N., Papayannis, A., and Nenes, A.: Biomass-burning impact on $\mathrm{CCN}$ number, hygroscopicity and cloud formation during summertime in the eastern Mediterranean, Atmos. Chem. Phys., 16, 7389-7409, doi:10.5194/acp-16-7389-2016, 2016.

Bowman, D. and Vigilante, T.: Conflagrations: the culture, ecology and politics of landscape burning in the north Kimberley, Ngoonjook, 38-45, 2001.

Bowman, D. M., Dingle, J. K., Johnston, F. H., Parry, D., and Foley, M.: Seasonal patterns in biomass smoke pollution and the mid 20th century transition from Aboriginal to European fire management in northern Australia, Global Ecol. Biogeogr., 16, 246-256, 2007.

Carrico, C. M., Petters, M. D., Kreidenweis, S. M., Sullivan, A. P., McMeeking, G. R., Levin, E. J. T., Engling, G., Malm, W. C., and Collett Jr., J. L.: Water uptake and chemical composition of fresh aerosols generated in open burning of biomass, Atmos. Chem. Phys., 10, 5165-5178, doi:10.5194/acp-10-5165-2010, 2010.

Carrico, C. M., Prenni, A. J., Kreidenweis, S. M., Levin, E. J., McCluskey, C. S., DeMott, P. J., McMeeking, G. R., Nakao, S., Stockwell, C., and Yokelson, R. J.: Rapidly evolving ultrafine and fine mode biomass smoke physical properties: Comparing laboratory and field results, J. Geophys. Res.-Atmos., 121, 57505768, 2016.

Carslaw, K. S., Boucher, O., Spracklen, D. V., Mann, G. W., Rae, J. G. L., Woodward, S., and Kulmala, M.: A review of natural aerosol interactions and feedbacks within the Earth system, Atmos. Chem. Phys., 10, 1701-1737, doi:10.5194/acp-10-17012010, 2010. 
Cerully, K. M., Bougiatioti, A., Hite Jr., J. R., Guo, H., Xu, L., Ng, N. L., Weber, R., and Nenes, A.: On the link between hygroscopicity, volatility, and oxidation state of ambient and water-soluble aerosols in the southeastern United States, Atmos. Chem. Phys., 15, 8679-8694, doi:10.5194/acp-15-8679-2015, 2015.

Chen, H., Sangster, J., Teng, T., and Lenzi, F.: A general method of predicting the water activity of ternary aqueous solutions from binary data, Can. J. Chem. Eng., 51, 234-241, 1973.

Dirksen, R. J., Folkert Boersma, K., De Laat, J., Stammes, P., Van Der Werf, G. R., Val Martin, M., and Kelder, H. M.: An aerosol boomerang: Rapid around the world transport of smoke from the December 2006 Australian forest fires observed from space, J. Geophys. Res.-Atmos., 114, D21201, doi:10.1029/2009JD012360, 2009.

Dusek, U., Frank, G., Hildebrandt, L., Curtius, J., Schneider, J., Walter, S., Chand, D., Drewnick, F., Hings, S., and Jung, D.: Size matters more than chemistry for cloud-nucleating ability of aerosol particles, Science, 312, 1375-1378, 2006.

Engelhart, G. J., Hennigan, C. J., Miracolo, M. A., Robinson, A. L., and Pandis, S. N.: Cloud condensation nuclei activity of fresh primary and aged biomass burning aerosol, Atmos. Chem. Phys., 12, 7285-7293, doi:10.5194/acp-12-7285-2012, 2012.

Fedele, R. M.: Observations of Australian Cloud Condensation Nuclei (CCN), RMIT University, 2015.

Gunthe, S. S., King, S. M., Rose, D., Chen, Q., Roldin, P., Farmer, D. K., Jimenez, J. L., Artaxo, P., Andreae, M. O., Martin, S. T., and Pöschl, U.: Cloud condensation nuclei in pristine tropical rainforest air of Amazonia: size-resolved measurements and modeling of atmospheric aerosol composition and CCN activity, Atmos. Chem. Phys., 9, 7551-7575, doi:10.5194/acp-9-75512009, 2009.

Gysel, M., McFiggans, G., and Coe, H.: Inversion of tandem differential mobility analyser (TDMA) measurements, J. Aerosol Sci., 40, 134-151, 2009.

Hennigan, C. J., Miracolo, M. A., Engelhart, G. J., May, A. A., Presto, A. A., Lee, T., Sullivan, A. P., McMeeking, G. R., Coe, H., Wold, C. E., Hao, W.-M., Gilman, J. B., Kuster, W. C., de Gouw, J., Schichtel, B. A., Collett Jr., J. L., Kreidenweis, S. M., and Robinson, A. L.: Chemical and physical transformations of organic aerosol from the photo-oxidation of open biomass burning emissions in an environmental chamber, Atmos. Chem. Phys., 11, 7669-7686, doi:10.5194/acp-11-7669-2011, 2011.

Johnson, G. R., Ristovski, Z., and Morawska, L.: Method for measuring the hygroscopic behaviour of lower volatility fractions in an internally mixed aerosol, J. Aerosol Sci., 35, 443-455, 2004.

Kaufman, Y., Hobbs, P., Kirchhoff, V., Artaxo, P., Remer, L., Holben, B., King, M., Ward, D., Prins, E., and Longo, K.: Smoke, Clouds, and Radiation-Brazil (SCAR-B) experiment, J. Geophys. Res.-Atmos., 103, 31783-31808, 1998.

Kondo, Y., Takegawa, N., Miyazaki, Y., Ko, M., Koike, M., Kita, K., Kawakami, S., Shirai, T., Ogawa, T., and Blake, D. R.: Effects of biomass burning and lightning on atmospheric chemistry over Australia and South-east Asia, Int. J. Wildland Fire, 12, 271-281, 2003.

Lawson, S. J., Keywood, M. D., Galbally, I. E., Gras, J. L., Cainey, J. M., Cope, M. E., Krummel, P. B., Fraser, P. J., Steele, L. P., Bentley, S. T., Meyer, C. P., Ristovski, Z., and Goldstein, A. H.: Biomass burning emissions of trace gases and particles in marine air at Cape Grim, Tasmania, Atmos. Chem. Phys., 15, 1339313411, doi:10.5194/acp-15-13393-2015, 2015.

Levin, E. J. T., Prenni, A. J., Palm, B. B., Day, D. A., CampuzanoJost, P., Winkler, P. M., Kreidenweis, S. M., DeMott, P. J., Jimenez, J. L., and Smith, J. N.: Size-resolved aerosol composition and its link to hygroscopicity at a forested site in Colorado, Atmos. Chem. Phys., 14, 2657-2667, doi:10.5194/acp-14-26572014, 2014.

Mallet, M. D., Desservettaz, M. J., Miljevic, B., Milic, A., Ristovski, Z. D., Alroe, J., Cravigan, L. T., Jayaratne, E. R., PatonWalsh, C., Griffith, D. W. T., Wilson, S. R., Kettlewell, G., van der Schoot, M. V., Selleck, P., Reisen, F., Lawson, S. J., Ward, J., Harnwell, J., Cheng, M., Gillett, R. W., Molloy, S. B., Howard, D., Nelson, P. F., Morrison, A. L., Edwards, G. C., Williams, A. G., Chambers, S. D., Werczynski, S., Williams, L. R., Winton, H. L., Atkinson, B., Wang, X., and Keywood, M. D.: Biomass burning emissions in north Australia during the early dry season: an overview of the 2014 SAFIRED campaign, Atmos. Chem. Phys. Discuss., doi:10.5194/acp-2016-866, in review, 2016.

Milic, A., Mallet, M. D., Cravigan, L. T., Alroe, J., Ristovski, Z. D., Selleck, P., Lawson, S. J., Ward, J., Desservettaz, M. J., PatonWalsh, C., Williams, L. R., Keywood, M. D., and Miljevic, B.: Aging of aerosols emitted from biomass burning in northern Australia, Atmos. Chem. Phys. Discuss., doi:10.5194/acp-2016-730, in review, 2016.

Mircea, M., Facchini, M. C., Decesari, S., Cavalli, F., Emblico, L., Fuzzi, S., Vestin, A., Rissler, J., Swietlicki, E., Frank, G., Andreae, M. O., Maenhaut, W., Rudich, Y., and Artaxo, P.: Importance of the organic aerosol fraction for modeling aerosol hygroscopic growth and activation: a case study in the Amazon Basin, Atmos. Chem. Phys., 5, 3111-3126, doi:10.5194/acp-53111-2005, 2005.

Mochida, M. and Kawamura, K.: Hygroscopic properties of levoglucosan and related organic compounds characteristic to biomass burning aerosol particles, J. Geophys. Res.-Atmos., 109, D21202, doi:10.1029/2004JD004962, 2004.

Novakov, T. and Corrigan, C.: Cloud condensation nucleus activity of the organic component of biomass smoke particles, Geophys. Res. Lett., 23, 2141-2144, 1996.

Noziere, B.: Don't forget the surface, Science, 351, 1396-1397, 2016.

Paramonov, M., Aalto, P. P., Asmi, A., Prisle, N., Kerminen, V.M., Kulmala, M., and Petäjä, T.: The analysis of size-segregated cloud condensation nuclei counter (CCNC) data and its implications for cloud droplet activation, Atmos. Chem. Phys., 13, 10285-10301, doi:10.5194/acp-13-10285-2013, 2013.

Petters, M. D. and Kreidenweis, S. M.: A single parameter representation of hygroscopic growth and cloud condensation nucleus activity, Atmos. Chem. Phys., 7, 1961-1971, doi:10.5194/acp-71961-2007, 2007.

Petters, M. D., Carrico, C. M., Kreidenweis, S. M., Prenni, A. J., DeMott, P. J., Collett, J. L., and Moosmüller, H.: Cloud condensation nucleation activity of biomass burning aerosol, J. Geophys. Res.-Atmos., 114, D22205, doi:10.1029/2009JD012353, 2009.

Platnick, S. and Twomey, S.: Determining the susceptibility of cloud albedo to changes in droplet concentration with the Advanced Very High Resolution Radiometer, J. Appl. Meteorol., 33, 334-347, 1994. 
Pöschl, U., Rose, D., and Andreae, M. O.: Climatologies of Cloudrelated Aerosols - Part 2: Particle Hygroscopicity and Cloud Condensation Nucleus Activity, in: Clouds in the Perturbed Climate System: Their Relationship to Energy Balance, Atmospheric Dynamics, and Precipitation, MIT Press, 58-72, 2009.

Pringle, K. J., Tost, H., Pozzer, A., Pöschl, U., and Lelieveld, J.: Global distribution of the effective aerosol hygroscopicity parameter for CCN activation, Atmos. Chem. Phys., 10, 52415255, doi:10.5194/acp-10-5241-2010, 2010.

Reid, J. S., Koppmann, R., Eck, T. F., and Eleuterio, D. P.: A review of biomass burning emissions - Part II: intensive physical properties of biomass burning particles, Atmos. Chem. Phys., 5, 799-825, doi:10.5194/acp-5-799-2005, 2005.

Reutter, P., Su, H., Trentmann, J., Simmel, M., Rose, D., Gunthe, S. S., Wernli, H., Andreae, M. O., and Pöschl, U.: Aerosol- and updraft-limited regimes of cloud droplet formation: influence of particle number, size and hygroscopicity on the activation of cloud condensation nuclei (CCN), Atmos. Chem. Phys., 9, 70677080, doi:10.5194/acp-9-7067-2009, 2009.

Ristovski, Z. D., Wardoyo, A. Y., Morawska, L., Jamriska, M., Carr, S., and Johnson, G.: Biomass burning influenced particle characteristics in Northern Territory Australia based on airborne measurements, Atmos. Res., 96, 103-109, 2010.

Rose, D., Nowak, A., Achtert, P., Wiedensohler, A., Hu, M., Shao, M., Zhang, Y., Andreae, M. O., and Pöschl, U.: Cloud condensation nuclei in polluted air and biomass burning smoke near the mega-city Guangzhou, China - Part 1: Size-resolved measurements and implications for the modeling of aerosol particle hygroscopicity and CCN activity, Atmos. Chem. Phys., 10, 33653383, doi:10.5194/acp-10-3365-2010, 2010.

Rose, D., Gunthe, S. S., Su, H., Garland, R. M., Yang, H., Berghof, M., Cheng, Y. F., Wehner, B., Achtert, P., Nowak, A., Wiedensohler, A., Takegawa, N., Kondo, Y., Hu, M., Zhang, Y., Andreae, M. O., and Pöschl, U.: Cloud condensation nuclei in polluted air and biomass burning smoke near the mega-city Guangzhou, China - Part 2: Size-resolved aerosol chemical composition, diurnal cycles, and externally mixed weakly $\mathrm{CCN}$-active soot particles, Atmos. Chem. Phys., 11, 2817-2836, doi:10.5194/acp-112817-2011, 2011.

Ross, K., Piketh, S., Bruintjes, R., Burger, R., Swap, R., and Annegarn, H.: Spatial and seasonal variations in $\mathrm{CCN}$ distribution and the aerosol-CCN relationship over southern Africa, J. Geophys. Res.-Atmos., 108, 8481, doi:10.1029/2002JD002384, 2003.
Russell-Smith, J., Yates, C. P., Whitehead, P. J., Smith, R., Craig, R., Allan, G. E., Thackway, R., Frakes, I., Cridland, S., and Meyer, M. C.: Bushfires "down under": patterns and implications of contemporary Australian landscape burning, Int. J. Wildland Fire, 16, 361-377, 2007.

Sánchez Gácita, M., Longo, K. M., Freire, J. L. M., Freitas, S. R., and Martin, S. T.: Impact of mixing state and hygroscopicity on CCN activity of biomass burning aerosol in Amazonia, Atmos. Chem. Phys., 17, 2373-2392, doi:10.5194/acp-17-23732017, 2017.

Spracklen, D. V., Carslaw, K. S., Pöschl, U., Rap, A., and Forster, P. M.: Global cloud condensation nuclei influenced by carbonaceous combustion aerosol, Atmos. Chem. Phys., 11, 9067-9087, doi:10.5194/acp-11-9067-2011, 2011.

Stokes, R. and Robinson, R.: Interactions in aqueous nonelectrolyte solutions, I. Solute-solvent equilibria, J. Phys. Chem., 70, 21262131, 1966.

Twomey, S.: Aerosols, clouds and radiation, Atmospheric Environment, Part A. General Topics, 25, 2435-2442, 1991.

van der Werf, G. R., Randerson, J. T., Giglio, L., Collatz, G. J., Kasibhatla, P. S., and Arellano Jr., A. F.: Interannual variability in global biomass burning emissions from 1997 to 2004, Atmos. Chem. Phys., 6, 3423-3441, doi:10.5194/acp-6-3423-2006, 2006.

Ward, D. S., Kloster, S., Mahowald, N. M., Rogers, B. M., Randerson, J. T., and Hess, P. G.: The changing radiative forcing of fires: global model estimates for past, present and future, Atmos. Chem. Phys., 12, 10857-10886, doi:10.5194/acp12-10857-2012, 2012.

Warner, J. and Twomey, S.: The production of cloud nuclei by cane fires and the effect on cloud droplet concentration, J. Atmos. Sci., 24, 704-706, 1967.

Winton, V. H. L., Edwards, R., Bowie, A. R., Keywood, M., Williams, A. G., Chambers, S. D., Selleck, P. W., Desservettaz, M., Mallet, M. D., and Paton-Walsh, C.: Dry season aerosol iron solubility in tropical northern Australia, Atmos. Chem. Phys., 16, 12829-12848, doi:10.5194/acp-16-12829-2016, 2016. 